\title{
Incremental Validity of Character Measures Over the Big Five and Fluid intelligence in Predicting Academic Achievement
}

\author{
Anqing Zheng ${ }^{1}$, Daniel A. Briley ${ }^{1}$, Ross Jacobucci², \\ K. Paige Harden ${ }^{3,4}$, \& Elliot M. Tucker-Drob ${ }^{3,4}$ \\ ${ }^{1}$ Department of Psychology, University of Illinois at Urbana-Champaign \\ ${ }^{2}$ Department of Psychology, University of Notre Dame \\ ${ }^{3}$ Department of Psychology, University of Texas at Austin \\ ${ }^{4}$ Population Research Center, University of Texas at Austin
}

Running head: INCREMENTAL VALIDITY OF CHARACTER

Address correspondence to: Anqing Zheng (anqingz2@illinois.edu).

This draft is currently undergoing peer review.

\section{Acknowledgements}

Daniel A. Briley, Elliot M. Tucker-Drob, and K. Paige Harden were supported by Jacobs Foundation Research Fellowships. Tucker-Drob and Harden are Faculty Research Associates of the Population Research Center at the University of Texas at Austin, which is supported by NIH grant P2CHD042849. Data collection for the Texas Twin Project has been supported by NIH grants R01HD083613, R01HD092548, R21HD081437, R21AA023322, and R21AA020588. 


\begin{abstract}
Student characteristics like grit, need for cognition, intellectual self-concept, mastery orientation, school value, and growth mindset are important predictors of academic achievement. Yet, it remains unclear to what extent these proposed measures provide additional theoretical or empirical utility over established measures of general personality, such as the Big Five. Here, we examine whether character measures display incremental validity over and above the Big Five Inventory and measures of fluid intelligence when predicting academic performance in a large sample $(\mathrm{N}=1,583)$ of $3^{\text {rd }}$ through $8^{\text {th }}$ grade students. The results indicate that multiple character measures demonstrate incremental prediction, particularly need for cognition $\left(\Delta \mathrm{R}^{2}=6.5 \%\right.$ over personality, $\Delta \mathrm{R}^{2}=2.5 \%$ over personality and fluid intelligence) and school value $\left(\Delta \mathrm{R}^{2}=4.2 \%\right.$ over personality). Applying regularization techniques to identify a parsimonious solution, both coefficients for need for cognition and school value remained non-zero and accounted for unique variance. The incremental predictive power of individual character measures was primarily due to common variance across the character measures $\left(\Delta \mathrm{R}^{2}=11.5 \%\right.$ over personality, $9.3 \%$ over personality and fluid intelligence). Educationally-contextualized measures have utility for predicting achievement in addition to decontextualized behavioral and ability measures.
\end{abstract}

Keywords: Character, Big Five, Academic Achievement, Predictive Validity, Incremental Validity 


\section{Incremental Validity of Character Measures Over the Big Five and Fluid intelligence in Predicting Academic Achievement}

Recent educational initiatives have increasingly emphasized that students need more than cognitive skills to function optimally in the education system (Pellegrino \& Hilton, 2012). For example, the concept of "character" (i.e., educationally-contextualized measures relevant for achievement, see Peterson \& Seligman, 2004; Richardson et al., 2012; Wigfield \& Eccles, 2000), has captured the attention of the policy makers and the public (Tough, 2012). As part of social and emotional skills (Peterson \& Seligman, 2004; Duckworth \& Yeager, 2015), character measures aim to assess narrow, contextualized personal attributes that are independent from cognitive abilities, and actually make a difference in the classroom. Yet, recent controversies have emerged over whether character measures provide novel information over and above established, de-contextualized measures that captured broad descriptions of behaviors and also relate to student performance (e.g., the Big Five personality dimensions; Primi et al., 2016). One of the challenges of disentangling character measures from the Big Five is the lack of consensus about which constructs should be used to capture children's character (Halle \& Darling-Churchill, 2016). Another challenge is the potential overlap and shared similarities in underlying constructs of different measures (Abrahams et al., 2019), so it remains unclear whether and to what extent character measures provide novel information over and above other character measures. These issues highlight the need for inclusive data across a variety of measures to more conclusively examine the incremental validity of character measures.

Here, we addressed two primary research questions using eight character measures on a large $(N=1,583)$ sample of $3^{\text {rd }}$ through $8^{\text {th }}$ grade students: (1) Do some character measures display incremental predictive validity of academic achievement over and above the Big Five and fluid intelligence? (2) Do character measures display incremental predictive validity over 
and above common variance shared with other character measures? Additionally, to further maximize generalizability and establish reproducible associations among variables, we explore the sparse set of variables which possess the strongest associations with academic achievement using a variable selection algorithm.

\section{Established Psychological Correlates of Academic Performance and Character}

Measures

Individuals differ across a wide variety of psychological features that may play a role in academic development, such as paying attention, finding content intrinsically valuable, and carefully meeting due dates (Krapohl et al., 2014). Fluid intelligence tests are valid predictors of academic achievement (Furnham et al., 2003; Frey \& Detterman, 2004), and the metaanalytic correlation between the two is .56 (Strenze, 2007). This strong correlation likely emerges because fluid intelligence and academic achievement are developmentally intertwined (Kievit et al., 2017; Ritchie \& Tucker-Drob, 2018). Indicators of fluid intelligence, such as memory and abstract reasoning, are useful for engaging in learning in the classroom. Executive functions, including fundamental mental processes for storing, representing, and manipulating information, are very strongly correlated with fluid intelligence (Engelhardt et al., 2016) and correlate with achievement at a similar level as fluid intelligence (Best et al., 2011; Blair \& Razza, 2007). These cognitive skills likely help students learn and retain new information in the academic environment.

But, intelligence is not all that matters. Social and emotional factors describing attributes that are independent of intelligence also likely influence student learning. School is a social environment, full of distractions, with various demands on the student that are not strictly dependent on the ability to encode new information. Within the framework of the Big Five personality dimensions (i.e., extraversion, agreeableness, conscientiousness, neuroticism, and openness to experience; see John et al., 2008), conscientiousness and 
openness are most strongly associated with academic achievement (Poropat, 2009;

Chamorro-Premuzic \& Furnham, 2003; von Stumm et al., 2011). Specifically, Poropat (2009) reported meta-analytic correlations between conscientiousness and openness with achievement of .22 and .12 , respectively. Students with relatively high levels of conscientiousness may, for instance, turn in assignments on time or, study for exams diligently over extended periods of time (rather than attempting to cram the night before), and simply strive for achievement to a greater extent. Students with relatively high levels of openness may find challenging material more approachable and be intrinsically interested in academic topics. Each of these characteristics may help one obtain better grades in school, regardless of fluid intelligence.

\section{Do Character Measures Have Incremental Validity?}

Predictions of academic performance may be more accurate if they are based on the assessment of context-specific individual differences, beyond general personality and fluid intelligence (Chamorro-Premuzic \& Furnham, 2003; Robbins et al., 2004). Although being broad and fairly comprehensive is typically seen as a strength of measures of fluid intelligence and the Big Five, they may be too broad. In particular, broad measures may include domains not relevant to educational settings or miss individual differences specific to academic achievement (e.g., applied concepts, such as finding schooling valuable, would not be part of the Big Five content domain). Further, narrower facets of personality may be particularly predictive of academic achievement (Richardson et al., 2012; Briley, Domiteaux, et al., 2014; Duckworth et al., 2007). For example, narrower facets of conscientiousness are sometimes even stronger predictors of academic achievement than the broad trait (Paunonen \& Ashton, 2001). Similarly, occupational interests, a highly contextualized measure of individual differences, tend to account for more variance in occupational outcomes compared to personality or fluid intelligence (Rounds $\& \mathrm{Su}, 2014$ ). These results are at least in part 
because facets of conscientiousness and occupational interests reflect more specific, contextualized individual differences relevant to the criterion. In this study, we focus on eight character measures: grit, need for cognition, intellectual self-concept, achievement goal orientations (mastery, performance approach, and performance avoidance), school value, and growth mindset. Detailed definitions of these constructs and their relevance to academic development are presented in Table 1.

Each of these measures is somewhat correlated with fluid intelligence and The Big Five personality (Tucker-Drob et al., 2016; Soric et al., 2017). For example, individuals who report gritty behavior also tend to report conscientious behavior, and those who report higher levels of need for cognition also tend to perform a bit better on cognitive ability tasks (see Table 1 for more details). This construct overlap has prompted questions of whether character measures capture more than personality traits (Abrahams et al., 2019). It may be the case that different labels have been applied to the same construct (i.e., the jingle-jangle fallacy, see Marsh et al., 2019 for a recent analysis of this problem). Poor understanding of the construct domain of character measures can lead to two inferential problems.

First, construct overlap makes it difficult to determine the plausible behavioral mechanisms leading to personality-achievement associations. Taking school value as an example, Expectancy-Value Theory (Wigfield \& Eccles, 2000) would identify motivational factors driving increased determination to perform academically when students believe school will be valuable for their future. It may also be the case that individuals who find value in school tend to be conscientious students who always diligently complete their homework and study for exams. If these sorts of behaviors are the primary source of the association, then school value may be of limited utility for educational researchers. However, demonstrating that students who find school valuable tend to perform better academically, 
even after holding conscientiousness constant, would bolster the special role of task value for motivation.

Second, construct overlap may be so extreme as to render the constructs essentially identical. One of the most prominent examples for such an entangled association is between grit and conscientiousness (Credé et al., 2017). Recent research has shown that grit is largely synonymous with conscientiousness. Despite some minor differences in the theoretical scope and intended purpose, the argument is that grit is simply a new label for conscientiousness, albeit perhaps a slightly narrower version (meta-analytic $\rho=.84$, Credé et al. 2017). Nothing new is gained by introducing the concept, and in fact, much is lost by missing the connection to the large literature on conscientiousness-achievement associations. Put in statistical terms, after holding conscientiousness constant, grit would not be associated with achievement because very little if any individual differences remain. Although much research has examined the relation between grit and conscientiousness, relatively little evidence exists for the other character measures used in this study.

A related criticism of character measures is that many similar measures have been created without an overarching structural framework, such as the Big Five. This scale design process opens the possibility for independent researchers to create novel character measures which essentially replicate other scales. For example, there seems to be obvious content overlap between mastery goal orientation (i.e., wanting to learn for the sake of learning) and need for cognition (i.e., enjoying learning new things). It could be the case that these two measures operate much in the same way as grit and conscientiousness. The character measures selected for inclusion in this study sample widely from different areas of individual differences approaches to predicting academic achievement to test this critique. 
Empirical evidence is required to establish whether character measures possess any unique predictive variance over broad measures, and whether individual character measures exhibit incremental validity over one another.

\section{Previous Evidence of Incremental Validity}

Grit was found to predict achievement in addition to the Big Five in a large sample (N $=4642$; Rimfeld et al., 2016), although with relatively little incremental prediction $(\sim 1 \%$ increase in $\mathrm{R}^{2}$ ). Similar meta-analytic estimates have been reported (Credé et al, 2017). Need for cognition possessed roughly equivalent incremental validity after taking into account fluid intelligence in a small sample $(\mathrm{N}=93$; Furnham et al., 2009). Self-concept $(\mathrm{N}=4475$, Marsh et al., 2006) tends to display relatively larger incremental prediction when considering the Big Five. Goal orientations, especially mastery goal orientation and performance approach goal orientation (N's $\sim 500$, Soric et al., 2017) showed modest incremental prediction over conscientiousness and openness $\left(1-4 \%\right.$ increase in $\left.\mathrm{R}^{2}\right)$. For other character measures, such as school value or growth mindset, incremental validity estimates are unknown, but non-zero correlations with personality and fluid intelligence have been found (Briley, Domiteaux, et al., 2014; Tucker-Drob et al., 2016).

However, the past literature is difficult to integrate as most studies differ in features that may influence the association between characters and academic achievement. In fact, associations with individual differences measures have been found to vary across different achievement criteria (Spengler et al., 2013), different achievement domains (Meyer et al., 2019), and different age groups (Tetzner et al., 2019). Further, few studies have examined the association taking into account the covariance among character measures. Most similar to the current project and using somewhat overlapping data, Tucker-Drob et al. (2016) and Malanchini et al. (2019) documented the convergent validity of several character measures predicting academic achievement, as well as the Big Five Inventory (BFI) and fluid 
intelligence. However, these previous studies were primarily focused on documenting common variance among all the predictors, rather than testing whether and to what extent do measures of character provide incremental prediction over and above the Big Five and fluid intelligence.

Furthermore, most of these previous studies on incremental validity of character measures did not use latent variable modeling approaches, which when paired with weak measures of the Big Five, produces poor evidence of incremental validity (Westfall \& Yarkoni, 2016). It is possible that previous estimates of incremental validity are inflated for this reason. In a similar vein, issues of small sample sizes make the literature difficult to interpret because the expected incremental validity is likely to be relatively small, requiring large samples to precisely estimate (Fraley \& Vazire, 2014). Here, we use a latent variable approach on a large sample to overcome these limitations. In addition, we include a regularized modeling approach adapted to structural equation modeling to select variables for the most parsimonious model (Jacobucci et al., 2016).

\section{The Current Study}

Given the applied interest from policy makers, parents, and the public, evaluating whether character measures possess additional utility is critical. This report has three purposes: (1) to examine the incremental validity of character measures over and above other psychometric measures of personality and fluid intelligence in a large sample $(\mathrm{N}=1,583)$ of $3^{\text {rd }}$ through $8^{\text {th }}$ grade students; (2) to investigate the structure of covariation among different character measures in order to estimate a common character factor; and (3) select among character, personality and fluid intelligence measures to derive a sparse model that facilitates interpretation and maximizes generalization. This knowledge would help to advance research on character measures and provide guidance on selecting variables when the scale administration time is in short supply. 


\section{Method}

\section{Participants}

Data were drawn from the Texas Twin Project (Harden et al., 2013), an ongoing inlaboratory study of individual differences and academic performance in an ethnically and socioeconomically diverse population. The current dataset were part of the Texas Twin Project subprojects approved by the Institutional Review Board of the University of Texas at Austin as 2013-02-0011 (“The Genes and Development Study"), and 2014-11-0021 (“Cortisol, Socioeconomic Status, and Genetic Influence on Cognitive Development”); Participants were 1,583 primarily $3^{\text {rd }}$ through $8^{\text {th }}$ grade students. Participant age ranged from 7.80 to 15.25 years $(\mathrm{M}=1.99, \mathrm{SD}=1.79)$. The sample was $49.5 \%$ female, $75.6 \%$ White, $23.2 \%$ Hispanic, 7.4\% African-American, 2.5\% Asian and 1\% some other race or ethnicity. Participants were instructed to select all applicable race/ethnicities. The sample was also economically diverse with approximately a third of families receiving means-tested public assistance. Within the sample, 108 participants contributed two observations due to longitudinal follow-up. Given power concerns, we did not conduct any longitudinal analyses. Non-independence of longitudinal observations and drawing multiple participants from the same family was corrected using the complex survey option and the MLR (Robust Standard Error Maximum Likelihood) estimator of Mplus.

\section{Measures}

Measures included self-reports of character and the Big Five, three indicators of fluid intelligence, and four indicators of in-lab academic achievement. All measures had acceptable reliability (see Table 2 for descriptive statistics). Except for fluid intelligence and academic achievement, all measures were responded to on a 5-point Likert scale ranging from strongly disagree to strongly agree.

\section{Big Five Inventory}


The Big Five were measured using the child-version of the Big Five Inventory (BFI; John et al., 2008). Extraversion refers to a positive and assertive approach to the social and material world. Agreeableness refers to a prosocial and communal orientation in social situations. Conscientiousness refers to the will to achieve and impulse control. Neuroticism refers to experiencing fluctuating emotional states and negative emotion. Openness refers to the insight of an individual's mental and experiential life. To control for individual response sets, all items were ipsatized following the recommendations of John et al. (2008).

Grit

Students were asked about their perseverance and passion for long-term goals. We used the eight-item Grit Scale for Children to measure grit (Duckworth \& Quinn, 2009). An example item is "I finish whatever I begin".

\section{Need for Cognition}

Students were asked about their need and desire to engage in intellectually challenging tasks and experiences. This was measured using the nine-item, child version of the Need for Cognition Scale (Kokis et al., 2002). One representative item would be: "I would prefer complex to simple problems."

\section{Intellectual Self-Concept}

Students were asked about their self-perceived intellectual ability using the Intellectual Investment subscale of the Multidimensional Achievement-relevant Personality Scale (Briley, Domiteaux, et al., 2014). Participants rated their competence and capability to learn in academic settings. The item "I am smart" was also added to the inventory as a face valid indicator.

\section{Goal Orientation}

Student mastery, performance approach, and performance avoidance goal orientations were measured using three subscales from the Pattern of Adaptive Learning Scales (PALS; 
Midgley et al., 2000). Both mastery and performance approach orientation scales include five items, and the performance avoidance goal scale has four items. Example items for each of the scales are: "One of my goals in class is to learn as much as I can;" "One of my goal orientations is to show others that I'm good at my class work;" and "It's important to me that I don't look stupid in class";

\section{School Value}

Students were asked about their beliefs on the relevance of academic achievement for their future success in life. This was measured using the six-item Skepticism about the Relevance of School for Future Success scale from the PALS (Midgley et al., 2000). An example item is "Doing well in school doesn't improve my chances of having a good life when I grow up.”

\section{Growth Mindset}

Students were asked about their view on the malleability of the intelligence. This was measured using the six-item Mindset scale (Dweck, 2000). An example item is "You have a certain amount of intelligence, and you really can't do much to change it."

\section{Fluid Intelligence}

We tested fluid intelligence using Matrix Reasoning and Block Design tests from the Wechsler Abbreviated Scale of Intelligence-II (WASI-II; Wechsler, 2011) and Spatial Relations adapted from the Woodcock-Johnson Tests of Cognitive Abilities-III (Woodcock et al., 2001). We calculated sum scores based on the number of questions the participant answered correctly, which served as indicators of latent fluid intelligence

\section{Academic Achievement}

Verbal knowledge was assessed with the Vocabulary and Similarities tests from the WASI-II (Wechsler, 2011). Mathematics and reading achievement was assessed with the Calculations and Passage Comprehension tests from the Woodcock Johnson Tests of 
Achievement-III (Woodcock et al., 2001). Similar to fluid ability, we calculated sum scores based on the number of correct responses and used these scores as indicators of latent academic achievement.

\section{Analytic Approach}

We used latent structural equation models to test associations between different psychometric measures and achievement. First, we tested the incremental validity of each character measure individually in predicting academic achievement. Then we used a series of common factor models to compare the strength of associations among all character measures. Finally, we used regularized structural equation modeling to perform variable selection.

\section{Preliminary Analysis}

To reduce model complexity, we created parcels for each self-report measure (Rhemtulla, 2016). We divided the items for each measure into three parcels to represent each latent variable using an item-to-construct balance approach (Little et al., 2002). To construct the parcels, we carried out single construct confirmatory factor analyses. We allocated the top three highest loading items to each parcel; then we assigned the three lowest loading items to each of the parcels in reverse order. The mean of the assigned items was used to represent each parcel. We standardized all parcels to ensure all indicators were on a similar metric (which is particularly useful for regularization techniques).

To determine the statistical power of our sample, we conducted a Monte-Carlo simulation where we specified factor loadings and typical associations among the Big Five factors, character, and academic achievement based on previous research. The result indicated that we had $85.9 \%$ power to detect an incremental validity coefficient of .15, and we would have $82.9 \%$ power to detect an .2 incremental validity coefficient over a common character factor. 
We first specified eight models (one for each character factor) where achievement is regressed on the Big Five and the residual of the character factor after controlling for the Big Five (Model 1, see Figure 1). By explicitly modeling the residual, we provide a strict test of whether character measures possess incremental validity after taking into account the Big Five. Then we estimated base models where the association among character factors (entered as the residual) and achievement was fixed to zero. Thus, the pair of models provides a $1 d f$ test of whether including a parameter connecting non-Big Five variance in character to academic achievement improves model fit.

To infer whether the character measure provided incremental validity, we examined the effect size of the freely estimated path coefficient, difference in fit between the base model and Model 1 (Satorra-Bentler scaled nested $\chi^{2}$ difference test; Satorra \& Bentler, 2001), and the change in the outcome variance explained $\left(\Delta \mathrm{R}^{2}\right)$. If the model with the path from the residual of character to achievement fixed to zero fits significantly worse than when freely estimated, this result implies that the character measure possesses incremental validity, with $\Delta \mathrm{R}^{2}$ providing a meaningful effect size for the improvement. For interpretation of the path coefficients, we address the limits of our exploratory approach by following the suggestion of more stringent statistical significance criterion of $\mathrm{p}<.005$ (Benjamin et al., 2018). To assess the incremental validity of character measures above and beyond both the Big Five and the fluid intelligence, we followed the previous two steps except that the achievement was also regressed on fluid intelligence, and the residuals now controlled additionally for fluid intelligence (Model 1gf).

To examine the covariance among character measures and the unique predictive validity of each individual measure, we first conducted latent correlations of the construct (see Table 2), and then incorporated a common character factor specified using bi-factor model in the following models (as shown in Figure 2). Such bi-factor model separates 
variance common across all character indicators from variance specific to indicators of the same construct. Thus, we can explore whether associations with achievement are due primarily to variance that is shared regardless of what specific character measure is used rather than something unique to a certain domain.

Building upon the bi-factor model, we investigated whether a single common character factor could capture the criterion validity across all character factors, and whether such a common character factor was associated with academic achievement over and beyond the Big Five (Model 2) and additionally the fluid intelligence (Model 2s). Next, we fitted a series of models (Model 3-3gf) allowing for direct paths from the individual character factor to the achievement factor in addition to the common effect (see Figure 2), and compared these models with Model 2-2gf in terms of $\Delta \chi^{2}$ and $\Delta \mathrm{R}^{2}$. Put differently, we identified whether character measures have incremental validity beyond the variance shared in common by all measures of character and general measures of personality and fluid intelligence.

In addition to fitting a bi-factor model, we were interested in using a hierarchical model to capture commonality among character measures, which partitions variance differently than the bi-factor models. The bi-factor structure of the common character factor fitted the data better $(\Delta \chi 2(12)=99.1898, p<.001 ; \Delta \mathrm{CFI}=.012 ; \Delta \mathrm{RMSEA}=.008)$. Therefore, we focus on results from the bi-factor model here and present parallel results using the hierarchical specification in the online supplement (see Appendix 3 and 5). Our primary conclusions hold across both modeling approaches.

\section{Selection Among Character Measures}

To maximize generalizability and avoid overfitting, we used regularization approach to select a parsimonious set of measures. We used regularized SEM (regSEM) as suggested by Jacobucci et al (2016) and used the adaptive least absolute shrinkage and selection operator (adaptive lasso; Zou, 2006) to stabilize the estimates. The adaptive lasso in SEM 
builds on the traditional maximum likelihood estimation in the SEM framework and tries to drive the byproduct of a tuning parameter $(\lambda)$ and sums of absolute value of estimates to zero $^{1}$. The goal of the algorithm is to allow as few parameters as possible to obtain non-zero estimates, leading to a subset of selected variables. This process centers interpretation on robust associations, hopefully increasing the generalizability of the penalized model. We fitted a model where all of the eight character factors, the Big Five factors, and the fluid intelligence factors were treated as predictors of achievement. We additionally fitted a model excluding the fluid intelligence to get a sparser representation focusing on social, emotional and behavioral factors. We residualized all the indicators and predictors for effects of age, sex and age $\times$ sex. In contrast to our inclusion of age and sex explicitly in our structural models (see Figure 1), we chose to residualize the variables prior to analysis to ensure age and sex were always controlled for rather than testing whether their association might be minimized. Then we penalized the prediction validities for these 14 variables using regSEM across 50 penalty values ranged from 0 to 1 . Following Jacobucci et al. (2019) suggestion, we used BIC (Bayesian information criterion; Schwarz, 1978) to select the best model solution over value of $\lambda$. The non-zero parameters in this best solution are corresponded to the selected variables for the sparsest model.

All analyses except for the regularization were conducted with Mplus 8.0 through the MplusAutomation package in R (Hallquist \& Wiley, 2018; R Core Team, 2019) using full information maximum likelihood estimation to account for missing data (Muthén \& Muthén, 1998-2017). All models control for age and sex effects. We corrected standard errors by

\footnotetext{
${ }^{1}$ In contrast to the lasso, the adaptive lasso gives each penalized parameter its own penalty, typically evidencing less bias for large parameters (Tibshirani, 1996).
} 
using TYPE=COMPLEX option and the cluster option in Mplus using family identifier to account for non-independence of observations stemming from including individuals from the same family and for repeated measurements of some participants (McNeish et al., 2017). The adaptive lasso analyses were run using the OpenMx package in $\mathrm{R}$, which allowed for regularization to be integrated with full information maximum likelihood estimation ${ }^{2}$ (Boker et al., 2011). The analytic plan for the first two questions was pre-registered before analyzing the data on OSF, and all analytic scripts are available (https://osf.io/9q3az/?view_only=9e6a2ba096664ea7b5299eb913487c6a). We included the variable selection analysis to simplify our complex model and synthesize factors that would most likely predict achievement outcomes in an alternative data set.

\section{Results}

\section{Descriptive Statistics}

Basic descriptive information is reported for all study outcomes in Table 2 and Appendix 2. All variables were approximately normally distributed, except for mastery goal orientation, which displayed ceiling effects. ${ }^{3}$ Table 2 presents correlations between the primary study variables at the latent variable level, controlling for age, sex, and age $\times$ sex effects. Our results showed that the parcels loaded appropriately on their respective factors, with the loadings ranging from .30 (for neuroticism) to .9 (for growth mindset).

\footnotetext{
${ }^{2}$ We did not incorporate the survey weights for adaptive lasso as we did not compute the standard errors of the estimates.

${ }^{3}$ We corrected the nonnormality by using CENSORED option in Mplus and fit the initial bi-factor structural model using Tobit link functions (Tobin, 1958). The results were similar to models without the specification. Since the Tobit approach is computationally demanding and can cause model non-convergence, we report results of models without Tobit approach hereafter.
} 
As expected, all character measures showed small, positive correlations with objective achievement measures ( $r$ 's ranged from .02 to .43), except for performance approach goal orientation $(\mathrm{r}=-.14)$. We replicated previous findings and found a moderate correlation between reports of school value and growth mindset with academic performance ( $r$ 's .35 and .22 , respectively). The correlation between need for cognition and achievement in the current sample was stronger than what been previously found ( $r=.43$, meta-analytic $r$ $=.19$ with GPA; Richardson et al., 2012).

\section{Incremental Validity of Individual Character Measures}

Model fit was generally acceptable across each model for Model 1-1s (see Table 3). We did not explore modification indices to improve model fit to avoid overfitting. Focusing first on results only controlling for the Big Five, model comparisons show that models with need for cognition $\left(\Delta \mathrm{R}^{2}=6.5 \%, \Delta \chi 2(1)=157.80\right)$, intellectual self-concept $\left(\Delta \mathrm{R}^{2}=1.9 \%, \Delta\right.$ $\chi 2(1)=8.595)$, school value $\left(\Delta \mathrm{R}^{2}=4.2 \%, \Delta \chi 2(1)=62.117\right)$ and growth mindset $\left(\Delta \mathrm{R}^{2}=\right.$ $2.6 \%, \Delta \chi 2(1)=78.956)$ did significantly and positively predict academic achievement beyond the Big Five measures ( $\beta$ 's range between .127 to .310 ).

Among the Big Five scales, openness to experience significantly predicted academic performance across models, whereas conscientiousness did not significantly predict achievement. These pattern of results for conscientiousness and openness may be due to our use of in-lab achievement tests instead of school year GPA to indicate academic performance. Such results were consistent with previous findings (e.g., Spengler et al., 2013), where openness showed stronger associations with achievement test scores, and conscientiousness was more closely related to grades. When additionally including fluid intelligence in the model with the Big Five, the latent fluid intelligence and the five personality factors contributed $59.8 \%$ of the total variance in achievement. 
After including fluid intelligence into the model (Model 1gf), all eight character measures significantly predicted academic achievement, except for performance-approach and performance-avoidance goal orientation. This result most likely occurred because fluid intelligence is a strong predictor of achievement $(\mathrm{r}=.76)$ but was largely unrelated to the character measures. The magnitude of incremental predictive validity for each character measure did not largely differ after the inclusion of fluid intelligence. The variance explained incrementally by all those character factors was modest $\left(\Delta \mathrm{R}^{2} \mathrm{~s}\right.$ range between $-.1 \%$ to $\left.2.5 \%\right)$.

\section{Incremental Validity of a Common Character Factor}

The bi-factor structure of the common character factor fitted the data well (CFI $=.932, \mathrm{TLI}=.910, \mathrm{RMSEA}=.038)$, with adequate factor loadings on each parcel ranged from .25 to .67; see Table 4). We excluded the performance approach and performance avoidance goal orientation when constructing the common character factor as they shared low covariance with other factors and did not show any incremental validity from the previous models. The common character factor showed a strong positive association with achievement ( $\beta=.343, \Delta \mathrm{R}^{2}=11.5 \%$ over the Big Five measures), and the positive association $\left(\beta=.305, \Delta \mathrm{R}^{2}=9.3 \%\right.$ over the Big Five and fluid intelligence) was only attenuated slightly with fluid intelligence additionally included in the $\operatorname{model}^{4}$.

Next, we were interested in whether individual character measures possess unique effects beyond the common character factor (Model 3-3s; Table 4 and Figure 2). Need for

\footnotetext{
${ }^{4}$ Interestingly, conscientiousness consistently displayed a modest negative association with achievement in the context of the bi-factor model of character. In the Model 2-2s, conscientiousness was a strong predictor of common character $(\beta=.625)$, which means the total effect of conscientiousness was fairly small, consistent with the small zero-order association.
} 
cognition, school value and growth mindset had unique positive associations with achievement beyond the common character factor ( $\beta$ 's ranged from .094 to $.157, \Delta \chi 2(1)$ ranged from 9.091 to 12.874 ). The $\mathrm{R}^{2}$ after including those individual pathways did not meaningfully increase, which could be due to the instability of the converged solution when computing a model with many parameters. This result indicates that the unique variances of school value, need for cognition, and growth mindset that are not shared with other character measures are associated with academic achievement. ${ }^{5}$ When fluid intelligence was included in the model, only school value remained having unique predictive validity (Models 3s).

For the higher-order models, the results are shown in Appendix 3, and they aligned with previous results from Model 2-3s, albeit with some differences in magnitude. The common character factor showed a similarly strong positive association with achievement ( $\beta$ $\left.=.350, \Delta \mathrm{R}^{2}=12.1 \%\right)$, as well when fluid intelligence was additionally included $(\beta=.310$, $\Delta \mathrm{R}^{2}=12.0 \%$ ). Among models testing unique effects of individual character measures, we found that the common character factor was associated with achievement across all models, except when including need for cognition. For need for cognition, however, the regression parameter of the direct pathway was large $(\beta=.305)$, possibly reflecting parameter

\footnotetext{
${ }^{5}$ We also observed a negative association between mastery orientation and achievement beyond the common character factor $\left(\beta=-.231, \Delta \chi 2(1)=42.604, \Delta \mathrm{R}^{2}=1.9 \%\right)$. Higher levels of mastery orientation appear to be negatively related to achievement, holding the common variance and all other variables constant. Compared to the modest correlation between mastery and achievement $(r=.11)$, and the nonsignificant incremental prediction of mastery over BFI $(\beta=.029)$, the regression coefficient of mastery in this model was much larger and switched signs. Further, the standardized coefficient of the common character increased from .47 to .57 , consistent with a classic suppression effect (Tzelgov \& Henik, 1991). For this reason, we view this mastery orientation result with skepticism.
} 
indetermination given that the loading of need for cognition on the common character factor was large (loading $=.803)^{6}$.

\section{Variable Selection Over Character, Big Five, and Fluid Intelligence Measures}

The summarized results can be found in Table 5, where the optimal BIC solution arrived at a $\lambda$ value of .428 . Here, we interpreted the coefficients as zero or nonzero given the regularized parameter estimates are biased toward zero (Tibshirani, 1996). The regularized model shrank 5 (extraversion, intellectual self-concept, grit, performance approach, and performance avoid) out of 14 parameters to zero. Given the high correlation between fluid intelligence and achievement, we additionally ran the regularization without the fluid intelligence factor to explore if the pattern would change. Four character measures remained non-zero across regularized models: need for cognition, school value, mindset, and (negatively) mastery goal orientation.

\footnotetext{
${ }^{6}$ In addition to the common character factor, previous work has identified a two-factor structure including a higher-order conscientiousness (HC) and openness (HO). The factor structure (see Appendix 6) is in congruence with that reported in Tucker-Drob et al. (2016) and Malanchini et al. (2019). All six character measures and openness and conscientiousness were summarized by HC and HO. Then we regressed the two superfactors on extraversion, agreeableness, and neuroticism. We encountered convergence issues when attempting to fit the model with conscientiousness and openness superfactors to the parcel-level data. As this set of analyses is a less direct test of whether character measures possess incremental validity over the Big Five, we chose to fit the model using domain-level data (i.e., manifest sum scores). We wanted to include this model in the report for completeness and to mirror the analytic steps of previous reports using this dataset. The primary conclusions hold true in this approach as well (see Appendix 4).
} 
Need for cognition and school value both showed non-zero estimates of incremental validity across most modeling approaches, demonstrating that contextualized character measures show benefits beyond the Big Five.

\section{Discussion}

This study investigated the power of several character measures to predict academic achievement over and above the Big Five and fluid intelligence. We also examined whether the associations between different character measures and achievement are driven by a common character factor, and whether some individual character measures have unique prediction beyond this common character factor. We found that the educationally contextualized measures did significantly predict variance in achievement even when the Big Five and fluid intelligence were included in the model. Much of the predictive validity was attributable to the common character factor, except for finding value in school for one's life, which held unique effects predicting achievement beyond the common character factor and across all specifications. The character measures we examined were diverse in their content, with some bearing large similarities to the Big Five (e.g., grit and need for cognition), others adopted from expectancy-value theory (e.g., school value and intellectual self-concept), or from meta-cognitive theories (e.g., growth mindset). Our results are consistent with educationally contextualized measures of achievement providing additional predictive power even when considering a wide range of psychological dimensions.

\section{Context-Specific Prediction}

We found incremental prediction for each measure in at least one specification. The magnitude of these incremental predictions tended to be fairly modest, with values for the character measures ranging between $.1-6.5 \%$ of the variance, compared to $17.8 \%$ of the variance being explained by the five domains of the Big Five. In this study, openness to experience, need for cognition and school value emerged as the strongest predictors of 
academic achievement, alongside traditional assessments of fluid intelligence. We also found incremental validity of growth mindset and competence-related beliefs (e.g., intellectual selfconcept) in predicting academic achievement, though the effect sizes were considerably smaller than those of need for cognition and school value. Similar results were found using regularization.

To our knowledge, this study is the first to investigate the incremental validity of growth mindset and school value above and beyond the Big Five scale. The results support the importance of task value in expectancy-value theory and highlight that this selfperception is not well captured by the Big Five. Our study also supports the finding of modest incremental predictive power of intellectual self-concept beyond the Big Five Inventory (Marsh et al., 2006). Furthermore, this study extended Dweck's $(2000,2006)$ research that having the belief that intelligence is malleable can benefit students, presumably by staying motivated and taking on new challenges. In contexts where length of survey is a concern, the current results and the regularization results point toward prioritizing openness, need for cognition and school value if the goal is to maximize prediction of academic achievement.

We found no support for the incremental validity of grit and achievement goal orientations in predicting academic achievement. In other words, the perseverance and passion for long-term goals (i.e., grit), the desire to learn for learning's sake (i.e., mastery orientation) and the desire to show competence (i.e., performance orientation) did not contribute unique prediction to academic achievement when holding personality constant. When including fluid intelligence along with personality, however, grit and mastery orientation showed modest incremental predictive validity for achievement, but performance orientation still showed null effects.

Apart from the fact that past studies have used different achievement criterion (e.g., GPA, SAT, or ACT as academic outcomes) compared to the current study (in-laboratory 
standardized tests), the divergent results might be explained by the fact that we used SEM instead of multiple regression to establish incremental validity. Using multiple regression to demonstrate incremental validity can be problematic due to issues of measurement error (Westfall \& Yarkoni, 2016).

Apart from these possibilities, the discrepancy could be explained by the fact that we used a younger cohort compared to previous studies. As shown by a meta-analysis by Sisk et al. (2018), the developmental stage of the students moderates the relation between growth mindset and academic achievement. Put differently, age could moderate the relations between character measures and academic achievement resulting in larger associations among middle school students compared to high school students. Younger students might be more influenced by the social and educational aspects that are assessed by character measures compared to older students. For these reasons, our estimates may be upper bounds on the likely unique prediction over other personality measures.

\section{Structure of Covariance Among Character Measures}

The common character factor was a strong predictor of academic achievement, and the magnitude of incremental validity of specific character measures was attenuated substantially after the inclusion of the common character factor. This result indicates that much of the covariance between specific character measures and achievement was attributable to the common character factor. Studies using broad assessment of the range of character and socioemotional skills may be better suited to identify associations with achievement.

In all, our attempt to close the gap between education-oriented and personalityoriented research has highlighted the importance of validating widely used educationally contextualized character measures against the backdrop of the established criterion validity of personality and fluid intelligence. The validation of character measures could lead to more 
accurate models of achievement and could be used to identify or intervene on students most in need.

\section{Limitations and Future Directions}

Despite a number of strengths, such as a large sample size, independent variables from different research areas, and using latent variable modeling to establish incremental validity, this study has some limitations. First, all of the character measures and the Big Five measure were based on child self-reports. Self-reports are known to be subject to common method biases (Podsakoff et al., 2003). To mitigate this potential bias, we indexed individuals' acquiescent response style and ipsatized the BFI items (John et al., 2008), implying that response sets are an unlikely explanation for our results. In addition to the valuable information provided by self-report, information from other informants can provide unique information about a person, such as parental report on child personality (Vazire, 2010). Future studies would benefit from including other raters of those measures. Importantly, our primary criterion, academic achievement, was not assessed with self-report which minimizes concerns about common method bias explaining our primary results.

Second, our study did not use real-world outcomes to measure academic achievement, such as grade point average. There are likely to be different psychological dimensions relevant to various forms of academic achievement. For example, test taking skills are likely to influence the measures used in the current study, whereas grades in school are less heavily weighted toward these sorts of skills. Instead, children can obtain good grades by turning in homework or other more effort-based tasks. These sorts of behaviors would be more likely to be associated with dimensions like conscientiousness. If we had included effort-based measures of achievement, we might have found significant associations with conscientiousness. Based on preliminary analyses combining in-laboratory assessments of achievement with school transcripts in the current sample $(\mathrm{N}=1235$, mean age $=1.64$ years, 
$\mathrm{SD}=1.76$ years), the tasks used in this study correlate strongly with school-based assessments. Specifically, the passage comprehension test was correlated at .56 with schoolbased reading scores, and school-based math scores correlated at .55 and .73 with calculations and applied problems, respectively. Currently, efforts to code the school-based assessments are ongoing.

Third, based on the current cross-sectional design, we are unable to distinguish the direction of effect between character measures and academic achievement. For instance, from the current results alone, it is not possible to determine whether individual differences in character precede and predict academic achievement or vice versa. Notably, a number of longitudinal studies demonstrate evidence that early character measures predict later academic performance (e.g., Briley, Harden, et al., 2014; DeBerard et al., 2004; Kearney et al., 2009). Thus, the associations between character measures and academic achievement are likely to partially represent directional effects of character on knowledge acquisition.

Fourth, the magnitude of incremental variance was modest, and the intervention implications remain unclear. However, compared to character measures that received substantial attention from the public and institutions (e.g., grit, mindset), our study found that school value and need for cognition may be better avenues for future work. We also found the common character factor to be the strongest predictor of achievement when controlling for personality and fluid intelligence. Moving forward, researchers interested in influencing academic achievement may benefit from taking a holistic perspective in which the commonalities of many socioemotional skills, personality tendencies, and cognitive skills are considered.

Finally, it is important to point out that this study was exploratory in nature, and we made no concrete predictions concerning which character measures would demonstrate incremental prediction before conducting the analyses. We did pre-register our analysis plan 
prior to examining the data. This approach helps to avoid data-driven exploratory results which are sample specific and derived from overfitting the data. We followed our preregistered plan with the following exceptions: Following preliminary feedback of this project, it was suggested to test a bi-factor model and to include performance approach goal orientation and performance avoidance goal orientation, which we did. We additionally included analyses on variable selection using regSEM to increase the generalizability of the sparse model to alternative data sets. Future studies using larger sample sizes should replicate our results.

\section{Conclusions}

An important step in validating measures is showing that the measures predict some consequential outcome. This study is the first to use latent variable modeling to evaluate incremental validity of a broad range of character measures over and above the Big Five and fluid intelligence. Our findings shed light on educationally contextualized measures and show that these constructs have the potential to improve models of academic development. We found that the educational characteristics of need for cognition and the school value predict academic achievement beyond personality measures and fluid intelligence, and that valuing school displays a unique association beyond the common character factor. The current results clarify the commonalities of contextualized character measures and broad personality dimensions. By focusing on measures with unique associations with achievement, succinct assessment inventories which maximize predictive power can be created to aid researchers in discovering methods to help students reach their maximum potential. 


\section{Reference}

Abrahams, L., Pancorbo, G., Primi, R., Santos, D., Kyllonen, P., John, O. P., \& De Fruyt, F. (2019). Social-emotional skill assessment in children and adolescents: Advances and challenges in personality, clinical, and educational contexts. Psychological Assessment, 31(4), 460.

Benjamin, D. J., Berger, J. O., Johannesson, M., Nosek, B. A., Wagenmakers, E. J., Berk, R., ... \& Cesarini, D. (2018). Redefine statistical significance. Nature Human Behaviour, 2(1), 6-1. https://doi.org/1.1038/s41562-017-0189-z

Best, J. R., Miller, P. H., \& Naglieri, J. A. (2011). Relations between executive function and academic achievement from ages 5 to 17 in a large, representative national sample. Learning and Individual Differences, 21(4), 327-336.

https://doi.org/1.1016/j.lindif.2011.01.007

Blair, C., \& Razza, R. P. (2007). Relating effortful control, executive function, and false belief understanding to emerging math and literacy ability in kindergarten. Child Development, 78(2), 647-663. https://doi.org/1.1111/j.1467-8624.2007.01019.x

Boker, S., Neale, M., Maes, H., Wilde, M., Spiegel, M., Brick, T., ... \& Mehta, P. (2011). OpenMx: an open source extended structural equation modeling framework. Psychometrika, 76(2), 306-317. https://doi.org/1.1007/s11336-010-9200-6

Briley, D. A., Domiteaux, M., \& Tucker-Drob, E. M. (2014). Achievement-relevant personality: Relations with the Big Five and validation of an efficient instrument. Learning and Individual Differences, 32, 26-39. h ttps://doi.org/1.1016/j.lindif.2014.03.010

Briley, D. A., Harden, K. P., \& Tucker-Drob, E. M. (2014). Child characteristics and parental educational expectations: Evidence for transmission with transaction. Developmental Psychology, 50(12), 2614-2632. https://doi.org/1.1037/a0038094 
Cacioppo, J. T., Petty, R. E., \& Feng Kao, C. (1984). The efficient assessment of need for cognition. Journal of Personality Assessment, 48(3), 306-307. https://doi.org/1.1207/s15327752jpa4803_13

Chamorro-Premuzic, T., \& Furnham, A. (2003). Personality predicts academic performance: Evidence from two longitudinal university samples. Journal of Research in Personality, 37(4), 319-338. https://doi.org/1.1016/S0092-6566(02)00578-0

Credé, M., Tynan, M. C., \& Harms, P. D. (2017). Much ado about grit: A meta-analytic synthesis of the grit literature. Journal of Personality and social Psychology, 113(3), 492511. https://doi.org/1.1037/pspp0000102

DeBerard, M. S., Spielmans, G., \& Julka, D. (2004). Predictors of academic achievement and retention among college freshmen: A longitudinal study. College Student Journal, 38(1), 66-8.

Duckworth, A. L., Peterson, C., Matthews, M. D., \& Kelly, D. R. (2007). Grit: perseverance and passion for long-term goals. Journal of Personality and Social Psychology, 92(6), 1087-1101. https://doi.org/1.1037/0022-3514.92.6.1087

Duckworth, A. L., \& Quinn, P. D. (2009). Development and validation of the Short Grit Scale (GRIT-S). Journal of Personality Assessment, 91(2), 166-174. https://doi.org/1.1080/00223890802634290

Duckworth, A. L., \& Yeager, D. S. (2015). Measurement matters: Assessing personal qualities other than cognitive ability for educational purposes. Educational Researcher, 44(4), 237-251. https://doi.org/1.3102/0013189X15584327

Dweck, C. S. (2000). Self-theories: Their role in motivation, personality and development. Philadelphia, PA: Psychology Press.

Dweck, C. S. (2006). Mindset: The new psychology of success. New York, NY: Random House. 
Elliot, A. J., \& Harackiewicz, J. M. (1996). Approach and avoidance achievement goals and intrinsic motivation: A mediational analysis. Journal of Personality and Social Psychology, 70, 461-475 https://doi.org/1.1037/0022-3514.7.3.461.

Engelhardt, L. E., Mann, F. D., Briley, D. A., Church, J. A., Harden, K. P., \& Tucker-Drob, E. M. (2016). Strong genetic overlap between executive functions and intelligence. Journal of Experimental Psychology: General, 145(9), 1141. https://doi.org/1.1037/xge0000195

Fleischhauer, M., Enge, S., Brocke, B., Ullrich, J., Strobel, A., \& Strobel, A. (2010). Same or different? Clarifying the relationship of need for cognition to personality and intelligence. Personality and Social Psychology Bulletin, 36(1), 82-96. https://doi.org/1.1177/0146167209351886

Frey, M. C., \& Detterman, D. K. (2004). Scholastic assessment or g? The relationship between the scholastic assessment test and general cognitive ability. Psychological Science, 15(6), 373-378. https://doi.org/1.1111/j.0956-7976.2004.00687.x

Furnham, A., Chamorro-Premuzic, T., \& McDougall, F. (2003). Personality, cognitive ability, and beliefs about intelligence as predictors of academic performance. Learning and Individual Differences, 14(1), 47-64. https://doi.org/1.1016/j.lindif.2003.08.002

Furnham, A., Monsen, J., \& Ahmetoglu, G. (2009). Typical intellectual engagement, Big Five personality traits, approaches to learning and cognitive ability predictors of academic performance. British Journal of Educational Psychology, 79(4), 769-782. https://doi.org/1.1348/978185409X412147

Halle, T. G., \& Darling-Churchill, K. E. (2016). Review of measures of social and emotional development. Journal of Applied Developmental Psychology, 45, 8-18. 
Hallquist, M. N., \& Wiley, J. F. (2018). MplusAutomation: An R package for facilitating large-scale latent variable analyses in Mplus. Structural Equation Modeling, 25, 621-638 https://doi.org/1.1080/10705511.2017.1402334.

Harden, K. P., Tucker-Drob, E. M., \& Tackett, J. L. (2013). The Texas twin project. Twin Research and Human Genetics, 16(1), 385-390.

Jacobucci, R., Grimm, K. J., \& McArdle, J. J. (2016). Regularized structural equation modeling. Structural Equation Modeling: A Multidisciplinary Journal, 23(4), 555-566. https://doi.org/1.1080/10705511.2016.1154793

Jacobucci, R., Brandmaier, A. M., \& Kievit, R. A. (2019). A practical guide to variable selection in structural equation modeling by using regularized multiple-indicators, multiple-causes models. Advances in Methods and Practices in Psychological Science, 2(1), 55-76. https://doi.org/1.1177/2515245919826527

John, O. P., Naumann, L. P., \& Soto, C. J. (2008). Paradigm shift to the integrative big five trait taxonomy. In O. P. John, R. W. Robins, \& L. A. Pervin (Eds.), Handbook of Personality: Theory and Research (3rd ed., pp. 114-158). New York, NY: Guilford.

Kokis, J. V., Macpherson, R., Toplak, M. E., West, R. F., \& Stanovich, K. E. (2002). Heuristic and analytic processing: Age trends and associations with cognitive ability and cognitive styles. Journal of Experimental Child Psychology, 83(1), 26-52. https://doi.org/1.1016/S0022-0965(02)00121-2

Kearney, E., Gebert, D., \& Voelpel, S. C. (2009). When and how diversity benefits teams: The importance of team members' need for cognition. Academy of Management Journal, 52(3), 581-598. https://doi.org/1.5465/amj.2009.41331431

Kievit, R. A., Lindenberger, U., Goodyer, I. M., Jones, P. B., Fonagy, P., Bullmore, E. T., ... \& Dolan, R. J. (2017). Mutualistic coupling between vocabulary and reasoning supports 
cognitive development during late adolescence and early adulthood. Psychological Science, 1419-1431. https://doi.org/1.1177/0956797617710785

Krapohl, E., Rimfeld, K., Shakeshaft, N. G., Trzaskowski, M., McMillan, A., Pingault, J. B., ... \& Plomin, R. (2014). The high heritability of educational achievement reflects many genetically influenced traits, not just intelligence. Proceedings of the National Academy of Sciences, 111(42), 15273-15278. https://doi.org/1.1073/pnas.1408777111

Little, T. D., Cunningham, W. A., Shahar, G., \& Widaman, K. F. (2002). To parcel or not to parcel: Exploring the question, weighing the merits. Structural Equation Modeling, 9(2), 151-173. https://doi.org/1.1207/S15328007SEM0902_1

Malanchini, M., Engelhardt, L. E., Grotzinger, A. D., Harden, K. P., \& Tucker-Drob, E. M. (2019). "Same but different": Associations between multiple aspects of self-regulation, cognition, and academic abilities. Journal of Personality and Social Psychology, 117(6), 1164-1188. http://dx.doi.org/1.1037/pspp0000224

Marsh, H. W., Pekrun, R., Parker, P. D., Murayama, K., Guo, J., Dicke, T., \& Arens, A. K. (2019). The murky distinction between self-concept and self-efficacy: Beware the lurking jingle-jangle fallacies. Journal of Educational Psychology, 111, 331-353.

Marsh, H. W., Trautwein, U., Lüdtke, O., Köller, O., \& Baumert, J. (2006). Integration of multidimensional self-concept and core personality constructs: Construct validation and relations to well-being and achievement. Journal of Personality, 74(2), 403-456. https://doi.org/1.1111/j.1467-6494.2005.0038.x

McNeish, D., Stapleton, L. M., \& Silverman, R. D. (2017). On the unnecessary ubiquity of hierarchical linear modeling. Psychological Methods, 22, 114-140 https://doi.org/1.1037/met0000078. 
Meyer, J., Fleckenstein, J., Retelsdorf, J., \& Köller, O. (2019). The relationship of personality traits and different measures of domain-specific achievement in upper secondary education. Learning and Individual Differences, 69, 45-59.

Midgley, C., Maehr, M. L., Hruda, L. Z., Anderman, E. M., Anderman, L. H., Freeman, K. E., . . Urdan, T. (2000). Manual for the Patterns of Adaptive Learning Scales (PALS). Ann Arbor, MI: University of Michigan.

Muthén, L.K. and Muthén, B.O. (1998-2017). Mplus User's Guide. Eighth Edition. Los Angeles, CA: Muthén \& Muthén.

Pellegrino, J. W., \& Hilton, M. L. (2012). Committee on defining deeper learning and 21st century skills. Center for Education.

Paunonen, S. V., \& Ashton, M. C. (2001). Big Five predictors of academic achievement. Journal of Research in Personality, 35(1), 78-9. https://doi.org/1.1037/00223514.81.3.524

Peterson, C., \& Seligman, M. E. P. (2004). Character strengths and virtues: A handbook and classification. Washington, DC, US: American Psychological Association; New York, NY, US: Oxford University Press.

Podsakoff, P. M., MacKenzie, S. B., Lee, J. Y., \& Podsakoff, N. P. (2003). Common method biases in behavioral research: a critical review of the literature and recommended remedies. Journal of Applied Psychology, 88(5), 879-903. https://doi.org/1.1037/0021901.88.5.879

Poropat, A. E. (2009). A meta-analysis of the five-factor model of personality and academic performance. Psychological Bulletin, 135(2), 322.

Primi, R., Santos, D., John, O. P., \& De Fruyt, F. (2016). Development of an inventory assessing social and emotional skills in Brazilian youth. European Journal of Psychological Assessment, 32(1), 5-16. 
Rhemtulla, M. (2016). Population performance of SEM parceling strategies under measurement and structural model misspecification. Psychological Methods, 21(3), 348368. http://dx.doi.org/1.1037/met0000072

Robbins, S. B., Lauver, K., Le, H., Davis, D., Langley, R., \& Carlstrom, A. (2004). Do psychosocial and study skill factors predict college outcomes? A metaanalysis. Psychological Bulletin, 130(2), 261. https://doi.org/1.1037/0033-2909.13.2.261

Richardson, M., Abraham, C., \& Bond, R. (2012). Psychological correlates of university students' academic performance: a systematic review and meta-analysis. Psychological Bulletin, 138(2), 353.

Rimfeld, K., Kovas, Y., Dale, P. S., \& Plomin, R. (2016). True grit and genetics: Predicting academic achievement from personality. Journal of Personality and Social Psychology, 111(5), 780-789.

Ritchie, S. J., \& Tucker-Drob, E. M. (2018). How much does education improve intelligence? A meta-analysis. Psychological Science, 29(8), 1358-1369. https://doi.org/1.1177/0956797618774253

Rounds, J., \& Su, R. (2014). The nature and power of interests. Current Directions in Psychological Science, 23(2), 98-103. http://dx.doi.org/1.1037/pspp0000089

R Core Team (2019). R: A language and environment for statistical computing. R Foundation for Statistical Computing, Vienna, Austria. URL http://www.R-project.org/.

Satorra, A., \& Bentler, P. M. (2001). A scaled difference chi-square test statistic for moment structure analysis. Psychometrika, 66(4), 507-514. https://doi.org/1.1007/BF02296192

Schwarz, G. (1978). Estimating the dimension of a model. The Annals of Statistics, 6(2), 461464.

Sisk, V. F., Burgoyne, A. P., Sun, J., Butler, J. L., \& Macnamara, B. N. (2018). To what extent and under which circumstances are growth mind-sets important to academic 
achievement? Two meta-analyses. Psychological Science, 29(4), 549-571.

ttps://doi.org/1.1177/0956797617739704

Sorić, I., Penezić, Z., \& Burić, I. (2017). The Big Five personality traits, goal orientations, and academic achievement. Learning and Individual Differences, 54, 126-134. https://doi.org/1.1016/j.lindif.2017.01.024

Spengler, M., Lüdtke, O., Martin, R., \& Brunner, M. (2013). Personality is related to educational outcomes in late adolescence: Evidence from two large-scale achievement studies. Journal of Research in Personality, 47(5), 613-625.

Strenze, T. (2007). Intelligence and socioeconomic success: A meta-analytic review of longitudinal research. Intelligence, 35(5), 401-426. https://doi.org/1.1016/j.intell.2006.09.004

Tetzner, J., Becker, M., \& Brandt, N. D. (2020). Personality-achievement associations in adolescence_- examining associations across grade levels and learning environments. Journal of Personality, 88(2), 356-372.

Tibshirani, R. (1996). Regression shrinkage and selection via the lasso. Journal of the Royal Statistical Society: Series B (Methodological), 58(1), 267-288. https://doi.org/1.1111/j.2517-6161.1996.tb0208.x

Tobin, J. (1958). Estimation of relationships for limited dependent variables. Econometrica: Journal of the Econometric Society, 24-36.

Tough, P. (2012). How children succeed: Grit, curiosity, and the hidden power of character. Boston, MA: Houghton Mifflin.

Tucker-Drob, E. M., Briley, D. A., Engelhardt, L. E., Mann, F. D., \& Harden, K. P. (2016). Genetically-mediated associations between measures of childhood character and academic achievement. Journal of Personality and Social Psychology, 111(5), 790-815. https://doi.org/1.1037/pspp0000098 
Tzelgov, J., \& Henik, A. (1991). Suppression situations in psychological research: Definitions, implications, and applications. Psychological Bulletin, 109(3), 524-538.

Vazire, S. (2010). Who knows what about a person? The self-other knowledge asymmetry (SOKA) model. Journal of Personality and Social Psychology, 98(2), 281-300 https://doi.org/1.1037/a0017908

Von Stumm, S., Hell, B., \& Chamorro-Premuzic, T. (2011). The hungry mind: Intellectual curiosity is the third pillar of academic performance. Perspectives on Psychological Science, 6(6), 574-588. https://doi.org/1.1177/1745691611421204

Westfall, J., \& Yarkoni, T. (2016). Statistically controlling for confounding constructs is harder than you think. PloS ONE, 11(3), e0152719. https:// doi.org/1.1371/journal.pone.0152719

Wigfield, A., \& Eccles, J. S. (2000). Expectancy-value theory of achievement motivation. Contemporary Educational Psychology, 25(1), 68-81.

Wigfield, A., Eccles, J. S., Fredricks, J. A., Simpkins, S., Roeser, R. W., \& Schiefele, U. (2015). Development of achievement motivation and engagement. In M. E. Lamb \& R. M. Lerner (Eds.), Handbook of Child Psychology and Developmental Science (7th ed., pp.657-700). New York, NY: John Wiley.

Zou, H. (2006). The adaptive lasso and its oracle properties. Journal of the American Statistical Association, 101(476), 1418-1429. ttps://doi.org/1.1198/016214506000000735 
Table 1

Character Constructs Definition and Description

\begin{tabular}{|c|c|c|c|}
\hline Measures & Construct Definition & Academic relevance & $\begin{array}{c}\text { Potential Personality } \\
\text { Trait and Intelligence } \\
\text { Overlap }\end{array}$ \\
\hline Grit & $\begin{array}{l}\text { Perseverance and passion for } \\
\text { long-term goals (Duckworth \& } \\
\text { Quinn, 2009) }\end{array}$ & $\begin{array}{l}\text { Grittier students may push through } \\
\text { difficult tasks and maintain focus } \\
\text { on their long-term goals }\end{array}$ & $\begin{array}{l}\text { Conscientiousness } \\
\text { (meta-analytic } r>.5, \\
\text { Credé et al., 2017). }\end{array}$ \\
\hline $\begin{array}{l}\text { Need for } \\
\text { cognition }\end{array}$ & $\begin{array}{l}\text { Enjoyment of engaging in } \\
\text { challenging tasks (Cacioppo et } \\
\text { al., 1984) }\end{array}$ & $\begin{array}{l}\text { Students with higher need for } \\
\text { cognition could find more } \\
\text { enjoyment in completing tasks that } \\
\text { require deep or challenging } \\
\text { thinking }\end{array}$ & $\begin{array}{l}\text { Openness }(\mathrm{r}=.41) \text {, fluid } \\
\text { intelligence (meta- } \\
\text { analytic } \mathrm{r}=.28 \text {; } \\
\text { Fleischhauer et al., } \\
2010)\end{array}$ \\
\hline $\begin{array}{l}\text { Intellectual } \\
\text { self-concept }\end{array}$ & $\begin{array}{l}\text { Self-views of competence, } \\
\text { capability, and intelligence in } \\
\text { the domain of learning (Briley } \\
\text { et al., 2014) }\end{array}$ & $\begin{array}{l}\text { Students with higher intellectual } \\
\text { self-concept form stronger } \\
\text { expectancies for success in school, } \\
\text { which in turn, increases effort put } \\
\text { toward learning. }\end{array}$ & $\begin{array}{l}\text { Conscientiousness and } \\
\text { openness }(\mathrm{r}=.23, .21 \\
\text { Marsh et al., 2006) }\end{array}$ \\
\hline $\begin{array}{l}\text { Achievement } \\
\text { goal } \\
\text { orientation }\end{array}$ & $\begin{array}{l}\text { Set of constructs that identify } \\
\text { sources of motivation (e.g., } \\
\text { mastery, performance- } \\
\text { approach, and performance- } \\
\text { avoidance ) for gaining or } \\
\text { demonstrating academic } \\
\text { competence (Elliot \& } \\
\text { Harackiewicz, 1996) }\end{array}$ & $\begin{array}{l}\text { Achievement goals describe how } \\
\text { students put their effort toward } \\
\text { learning: learning for learning's } \\
\text { sake (mastery), learning to do well } \\
\text { on exams (performance approach), } \\
\text { and learning to prevent showing } \\
\text { incompetence on tasks to other } \\
\text { students (performance avoid) }\end{array}$ & $\begin{array}{l}\text { Conscientiousness } \\
\left(\mathrm{r}_{\text {mastery }}=.29, \text { rp-approach }\right. \\
=.25, \text { rp-avoidance }=-.25) ; \\
\text { Openness }\left(\mathrm{r}_{\text {mastery }}=.20,\right. \\
\text { rp-approach }=.05, \text { rp-avoidance } \\
=-.05 ; \text { Sorić et al., } \\
2017)\end{array}$ \\
\hline School value & $\begin{array}{l}\text { Importance that students place } \\
\text { on academic achievement for } \\
\text { future success (Wigfield et al., } \\
2015 \text { ) }\end{array}$ & $\begin{array}{l}\text { Students who value school more } \\
\text { may tend to display greater } \\
\text { motivation and exert greater effort } \\
\text { toward learning academic material }\end{array}$ & $\begin{array}{l}\text { Not directly assessed in } \\
\text { the Big Five framework }\end{array}$ \\
\hline $\begin{array}{l}\text { Intelligence } \\
\text { growth } \\
\text { mindset }\end{array}$ & $\begin{array}{l}\text { Belief that intelligence is } \\
\text { malleable, and therefore effort } \\
\text { is worthwhile (Dweck, 2000) }\end{array}$ & $\begin{array}{l}\text { Students with growth mindset may } \\
\text { spend energy on academic topics } \\
\text { and push through tough obstacles } \\
\text { due to the possibility of growth. }\end{array}$ & $\begin{array}{l}\text { Not directly assessed in } \\
\text { the Big Five framework }\end{array}$ \\
\hline
\end{tabular}


Table 2

Latent Correlations Among Character Measures, Personality Traits, Gf, and Achievement

Partial Correlation (Controlled for age, sex, and age $\times$ sex $)$

\begin{tabular}{|c|c|c|c|c|c|c|c|c|c|c|c|c|c|c|}
\hline $\begin{array}{l}\text { Outcome } \\
\text { variable }\end{array}$ & Grit & Need & Int.S & Mast & Papp & Pavo & Sch.V & Mind & $\mathrm{E}$ & A & $\mathrm{C}$ & $\mathrm{N}$ & $\mathrm{O}$ & Gf \\
\hline \multicolumn{15}{|l|}{ Character } \\
\hline Grit & - & & & & & & & & & & & & & \\
\hline Need & $.52(.04)$ & - & & & & & & & & & & & & \\
\hline Int.S & $.39(.04)$ & $.63(.03)$ & - & & & & & & & & & & & \\
\hline Mast & $.42(.03)$ & $.53(.03)$ & $.41(.04)$ & - & & & & & & & & & & \\
\hline Papp & $-.04(.04)$ & $.01(.04)$ & $.17(.04)$ & $.28(.03)$ & & & & & & & & & & \\
\hline Pavo & $-.20(.04)$ & $-.06(.04)$ & $.15(.05)$ & $.12(.04)$ & $.79(.03)$ & & & & & & & & & \\
\hline Sch.V & $.35(.04)$ & $.36(.04)$ & $.24(.04)$ & $.35(.04)$ & $-.11(.04)$ & $-.15(.05)$ & - & & & & & & & \\
\hline Mind & $.19(.04)$ & $.29(.04)$ & $.17(.04)$ & $.20(.04)$ & $-.02(.03)$ & $-.07(.04)$ & $.24(.03)$ & - & & & & & & \\
\hline \multicolumn{15}{|c|}{ Personality (Ipstaized) } \\
\hline $\mathrm{E}$ & $.20(.04)$ & $.14(.04)$ & $.21(.04)$ & $.02(.03)$ & $.01(.04)$ & $-.02(.04)$ & $.15(.04)$ & $.11(.03)$ & - & & & & & \\
\hline A & $.43(.03)$ & $.20(.04)$ & $.04(.04)$ & $.19(.04)$ & $-.15(.04)$ & $-.17(.04)$ & $.33(.04)$ & $.16(.03)$ & $.41(.04)$ & - & & & & \\
\hline $\mathrm{C}$ & $.71(.03)$ & $.43(.03)$ & $.26(.04)$ & $.35(.04)$ & $.02(.03)$ & $-.07(.04)$ & $.29(.03)$ & $.23(.03)$ & $.36(.04)$ & $.70(.03)$ & - & & & \\
\hline $\mathrm{N}$ & $-.39(.04)$ & $-.27(.04)$ & $-.36(.04)$ & $-.20(.04)$ & $.00(.04)$ & $.04(.05)$ & $-.12(.04)$ & $-.11(.04)$ & $.03(.05)$ & $-.19(.05)$ & $-.16(.05)$ & - & & \\
\hline $\mathrm{O}$ & $.17(.04)$ & $.39(.04)$ & $.50(.04)$ & $.16(.04)$ & $-.11(.04)$ & $-.05(.04)$ & $.28(.04)$ & $.11(.03)$ & $.36(.04)$ & $.31(.04)$ & $.30(.04)$ & $.03(.04)$ & - & \\
\hline Gf & $.01(.04)$ & $.25(.04)$ & $.18(.04)$ & $.00(.04)$ & $-.10(.04)$ & $.12(.05)$ & $.20(.04)$ & $.12(.04)$ & $.02(.04)$ & $.08(.04)$ & $.09(.04)$ & $-.06(.04)$ & $.33(.04)$ & \\
\hline Ach & $.18(.04)$ & $.43(.04)$ & $.32(.04)$ & $.11(.04)$ & $-.14(.04)$ & $.02(.05)$ & $.35(.04)$ & $.22(.03)$ & $.10(.04)$ & $.15(.04)$ & $.14(.04)$ & $-.11(.04)$ & $.38(.04)$ & $.76(.03)$ \\
\hline $\mathrm{N}$ & 1292 & 1477 & 1310 & 1391 & 1417 & 1393 & 1410 & 1433 & 1482 & 1484 & 1484 & 1484 & 1484 & - \\
\hline$\alpha$ & .66 & .72 & .77 & .80 & .84 & .59 & .77 & .84 & .74 & .71 & .75 & .67 & .66 & - \\
\hline Mean & $3.25(.53)$ & $3.39(.58)$ & $3.74(.59)$ & $4.25(.72)$ & $\begin{array}{l}2.87 \\
(105)\end{array}$ & $3.00(.96)$ & $3.99(.88)$ & $3.34(.86)$ & $.04(.59)$ & $.42(.47)$ & $.20(.55)$ & $-.36(.53)$ & $.54(.44)$ & \\
\hline
\end{tabular}

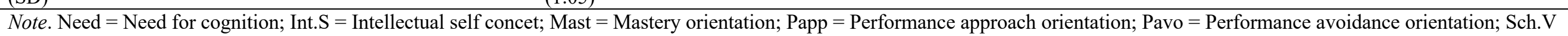

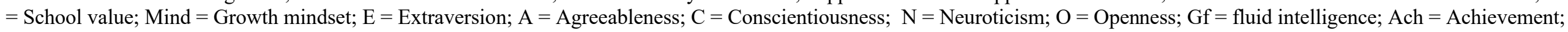

The standard errors are in the parenthesis. 
Table 3

Standardized Coefficients for Models with Character Measures and BFI (w/ Gf) Predicting Academic Performance

\begin{tabular}{|c|c|c|c|c|c|c|c|c|c|c|c|c|c|c|}
\hline \multirow[t]{2}{*}{ Predictors } & \multicolumn{7}{|c|}{$\beta$} & \multicolumn{7}{|c|}{ Model Fit } \\
\hline & Character & E & A & $\mathrm{C}$ & $\mathrm{N}$ & $\mathrm{O}$ & Gf & CFI & TLI & RMSEA & SRMR & $\begin{array}{l}\text { Fixed } \\
\text { set } R^{2}\end{array}$ & $\Delta \mathrm{R}^{2}$ & $\Delta \chi 2(1)$ \\
\hline \multicolumn{15}{|l|}{ Model 1} \\
\hline Grit & $.085(.06)$ & $-.032(.05)$ & $.055(.07)$ & $-.045(.07)$ & $-.099(.04)$ & $.416(.04)$ & - & .950 & .921 & .044 & .036 & .177 & .006 & 2.109 \\
\hline Need & $.310(.04)$ & $-.036(.05)$ & $.068(.07)$ & $-.060(.07)$ & $-.106(.04)$ & $.417(.04)$ & - & .950 & .921 & .044 & .034 & .209 & .065 & 157.796 \\
\hline Int.S & $.127(.05)$ & $-.034(.05)$ & $.063(.07)$ & $-.066(.07)$ & $-.104(.04)$ & $.421(.04)$ & - & .948 & .916 & .046 & .036 & .191 & .003 & 8.595 \\
\hline Mast & $.027(.04)$ & $-.029(.05)$ & $.074(.07)$ & $-.075(.07)$ & $-.101(.04)$ & $.420(.04)$ & - & .955 & .929 & .042 & .033 & .179 & .000 & .491 \\
\hline Papp & $-.086(.04)$ & $-.027(.05)$ & $.073(.07)$ & $-.078(.07)$ & $-.099(.04)$ & $.419(.04)$ & - & .955 & .929 & .043 & .033 & .183 & .002 & 6.358 \\
\hline Pavo & $.062(.04)$ & $-.028(.05)$ & $.075(.07)$ & $-.079(.07)$ & $-.100(.04)$ & $.420(.04)$ & - & .950 & .920 & .043 & .034 & .177 & .005 & 2.083 \\
\hline Sch.V & $.242(.04)$ & $-.037(.05)$ & $.075(.07)$ & $-.065(.07)$ & $-.105(.04)$ & $.416(.04)$ & - & .954 & .927 & .043 & .034 & .194 & .042 & 62.117 \\
\hline Mind & $.172(.03)$ & $-.028(.05)$ & $.076(.07)$ & $-.080(.07)$ & $-.100(.04)$ & $.419(.04)$ & - & .958 & .932 & .043 & .034 & .181 & .026 & 78.956 \\
\hline \multicolumn{15}{|l|}{ Model Igf } \\
\hline Grit & $.156(.04)$ & $.029(.04)$ & $.044(.06)$ & $-.013(.05)$ & $-.057(.04)$ & $.130(.04)$ & $.720(.04)$ & .951 & .925 & .042 & .035 & .596 & .025 & 14.359 \\
\hline Need & $.226(.04)$ & $.030(.04)$ & $.05(.06)$ & $-.021(.05)$ & $-.06(.04)$ & $.053(.05)$ & $.671(.04)$ & .951 & .925 & .042 & .034 & .626 & .025 & 125.633 \\
\hline Int.S & $.139(.04)$ & $.032(.04)$ & $.049(.06)$ & $-.024(.05)$ & $-.059(.04)$ & $.034(.06)$ & $.706(.04)$ & .948 & .921 & .043 & .035 & .604 & .013 & 14.977 \\
\hline Mast & $.086(.03)$ & $.030(.04)$ & $.053(.06)$ & $-.028(.05)$ & $-.059(.04)$ & $.125(.04)$ & $.710(.04)$ & .955 & .932 & .039 & .033 & .596 & .009 & 7.750 \\
\hline Papp & $-.046(.03)$ & $.031(.04)$ & $.053(.06)$ & $-.029(.05)$ & $-.058(.04)$ & $.136(.04)$ & $.699(.04)$ & .955 & .931 & .041 & .033 & .601 & -.001 & 2.576 \\
\hline Pavo & $-.044(.04)$ & $.031(.04)$ & $.054(.06)$ & $-.031(.05)$ & $-.058(.04)$ & $.136(.04)$ & $.711(.04)$ & .951 & .925 & .041 & .034 & .597 & .005 & 1.489 \\
\hline Sch.V & $.164(.03)$ & $.029(.04)$ & $.055(.06)$ & $-.028(.05)$ & $-.059(.04)$ & $.110(.04)$ & $.679(.04)$ & .955 & .931 & .040 & .033 & .616 & .006 & 44.526 \\
\hline Mind & $.113(.03)$ & $.032(.04)$ & $.054(.06)$ & $-.031(.05)$ & $-.059(.04)$ & $.138(.04)$ & $.692(.04)$ & .957 & .934 & .041 & .033 & .608 & .004 & 25.786 \\
\hline
\end{tabular}

Note. $\mathrm{N}=1499$. See diagram of models in Figure 1. Fixed set $\mathrm{R}^{2}$ represents sets of models where each character pathway to achievement was fixed to zero. The $\Delta \mathrm{R}^{2}$ for Model 1 and $1 \mathrm{~s}$ are derived by comparing with the fixed set $\mathrm{R}^{2}$. The standardization is relative to the residual variance. $\mathrm{CFI}=\mathrm{Comparative}$ fit index; $\mathrm{SRMR}=$ Standardized root mean square residual; RMSEA = Root mean square error of approximation. All models were fit using full information maximum likelihood estimation. All betas are standardized. All variables have been residualized for age, sex, and age $\times$ sex effect. The standard errors are in the parenthesis. The chisquared difference significant at $\mathrm{p}<.005$ level was bolded. 
Table 4

Standardized Coefficients of Bi-Factor Common Character Models, Personality, and Fluid Ability Predicting Academic Achievement

\begin{tabular}{|c|c|c|c|c|c|c|c|c|c|c|c|c|c|c|}
\hline \multirow[b]{2}{*}{ Outcome } & \multicolumn{8}{|c|}{$\beta$} & \multicolumn{6}{|c|}{ Model Fit } \\
\hline & Common $\mathrm{C}$ & Character & $\mathrm{E}$ & A & $\mathrm{C}$ & $\mathrm{N}$ & $\mathrm{O}$ & Gf & CFI & TLI & RMSEA & SRMR & $\Delta \mathrm{R}^{2}$ & $\Delta \chi 2(1)$ \\
\hline \multicolumn{15}{|c|}{ Model 2: Common Character Including Personality } \\
\hline Common $\mathrm{C}$ & $.343(.05)$ & - & $-.039(.05)$ & $.055(.07)$ & $-.040(.07)$ & $-.109(.04)$ & $.414(.04)$ & - & .932 & .910 & .038 & .045 & .116 & - \\
\hline \multicolumn{15}{|c|}{ Model 3: Common Character and Direct Effects of Character Measures } \\
\hline Grit & $.349(.05)$ & $-.117(.05)$ & $-.041(.05)$ & $.054(.07)$ & $-.008(.07)$ & $-.114(.04)$ & $.397(.04)$ & - & .932 & .910 & .038 & .045 & .014 & 5.488 \\
\hline Need & $.275(.05)$ & $.157(.05)$ & $-.037(.05)$ & $.066(.07)$ & $-.045(.07)$ & $-.116(.04)$ & $.408(.04)$ & - & .932 & .911 & .038 & .045 & -.016 & 9.091 \\
\hline Int.S & $.354(.05)$ & $-.053(.05)$ & $-.035(.05)$ & $.044(.07)$ & $-.045(.07)$ & $-.116(.04)$ & $.424(.04)$ & - & .932 & .910 & .038 & .045 & .017 & 1.255 \\
\hline Mast & $.435(.05)$ & $-.231(.04)$ & $-.060(.05)$ & $.065(.07)$ & $-.034(.07)$ & $-.097(.04)$ & $.395(.04)$ & - & .934 & .912 & .038 & .045 & .109 & 42.245 \\
\hline Sch.V & $.298(.05)$ & $.156(.04)$ & $-.038(.05)$ & $.010(.07)$ & $-.008(.07)$ & $-.123(.04)$ & $.409(.04)$ & - & .933 & .911 & .038 & .045 & -.009 & 12.874 \\
\hline Mind & $.323(.05)$ & $.094(.03)$ & $-.042(.05)$ & $.051(.07)$ & $-.042(.07)$ & $-.111(.04)$ & $.420(.04)$ & - & .932 & .910 & .038 & .045 & -.001 & 1.138 \\
\hline \multicolumn{15}{|c|}{ Model 2gf: Common Character Including Personality and Fluid intelligence } \\
\hline Common $\mathrm{C}$ & $.305(.04)$ & - & $.029(.04)$ & $.042(.06)$ & $-.011(.05)$ & $-.061(.04)$ & $.130(.04)$ & $.706(.04)$ & .933 & .913 & .037 & .045 & .093 & - \\
\hline \multicolumn{15}{|c|}{ Model 3gf: Common Character and Direct Effects of Character Measures Including Personality and Fluid intelligence } \\
\hline Grit & $.308(.04)$ & $-.039(.04)$ & $.028(.04)$ & $.042(.06)$ & $-.001(.06)$ & $-.063(.04)$ & $.125(.04)$ & $.706(.04)$ & .933 & .913 & .037 & .044 & .002 & .928 \\
\hline Need & $.276(.04)$ & $.073(.04)$ & $.030(.04)$ & $.047(.06)$ & $-.013(.05)$ & $-.065(.04)$ & $.129(.04)$ & $.703(.04)$ & .933 & .913 & .037 & .044 & -.014 & 2.626 \\
\hline Int.S & $.317(.04)$ & $-.055(.04)$ & $.034(.04)$ & $.031(.06)$ & $-.017(.05)$ & $-.069(.04)$ & $.141(.04)$ & $.703(.04)$ & .933 & .913 & .037 & .045 & .012 & 1.942 \\
\hline Mast & $.368(.04)$ & $-.148(.04)$ & $.015(.04)$ & $.048(.06)$ & $-.007(.05)$ & $-.054(.04)$ & $.123(.04)$ & $.699(.04)$ & .934 & .914 & .036 & .044 & .048 & 18.985 \\
\hline Sch.V & $.278(.04)$ & $.098(.03)$ & $.030(.04)$ & $.016(.06)$ & $.006(.05)$ & $-.070(.04)$ & $.131(.04)$ & $.701(.04)$ & .934 & .914 & .036 & .044 & -.014 & 7.972 \\
\hline Mind & $.294(.04)$ & $.060(.03)$ & $.027(.04)$ & $.040(.06)$ & $-.012(.05)$ & $-.063(.04)$ & $.136(.04)$ & $.703(.04)$ & .934 & .913 & .037 & .044 & -.004 & 5.652 \\
\hline
\end{tabular}

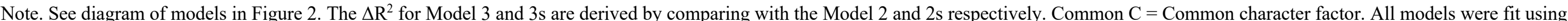

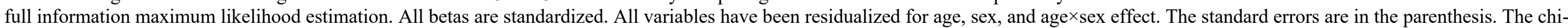
squared difference significant at $\mathrm{p}<.005$ level were bolded. 
Table 5

Fully Standardized Regression Parameters From the Adaptive Lasso Models

\begin{tabular}{|c|c|c|}
\hline Predictor & $\begin{array}{l}\text { Including BFI and } \\
\text { Gf }\end{array}$ & $\begin{array}{l}\text { Including } \\
\text { BFI }\end{array}$ \\
\hline $\mathrm{E}$ & .000 & -.028 \\
\hline A & .040 & .000 \\
\hline $\mathrm{C}$ & -.137 & -.150 \\
\hline $\mathrm{N}$ & -.086 & -.092 \\
\hline $\mathrm{O}$ & .194 & .281 \\
\hline Gf & 1.474 & - \\
\hline Grit & .000 & .000 \\
\hline Need & .402 & .407 \\
\hline Int.S & .000 & -.010 \\
\hline Mast & -.133 & -.235 \\
\hline Papp & .000 & .000 \\
\hline Pavo & .000 & .000 \\
\hline Sch.V & .366 & .409 \\
\hline Mind & .185 & .189 \\
\hline$\lambda$ & .428 & 1.141 \\
\hline $\mathrm{BIC}$ & 184992.121 & 174966.991 \\
\hline
\end{tabular}

Note. Gf = Fluid Intelligence. 


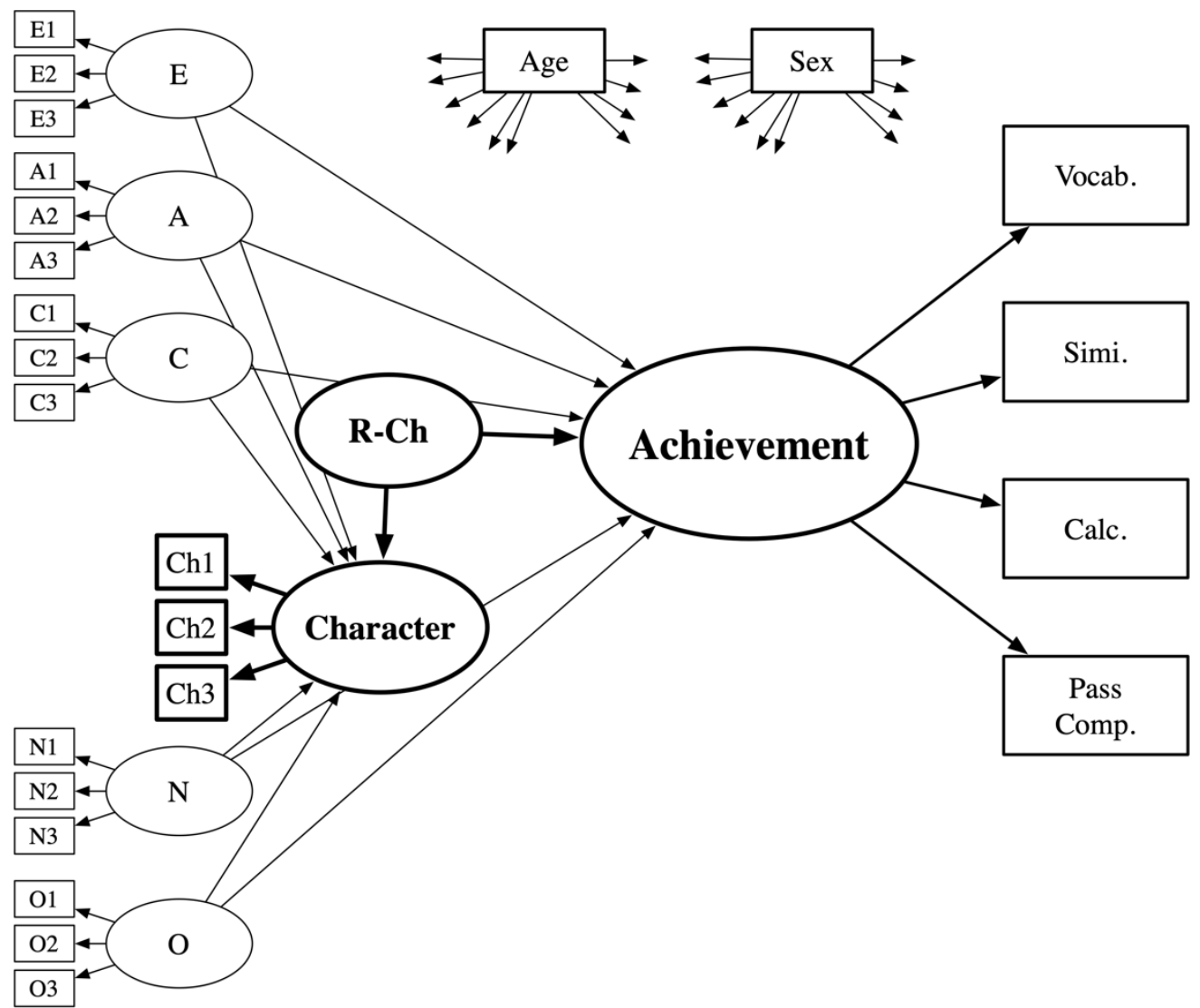

Figure 1. Example structural equation model testing incremental prediction of character over and above the Big Five. Each self-reported predictor is based on three parcels. $\mathrm{R}-\mathrm{Ch}=$ residual of character factor after controlling for the Big Five; Vocab $=$ Vocabulary test Simi $=$ Similarity test Calc $=$ Calculations test; Pass Comp= Passage comprehension test. 


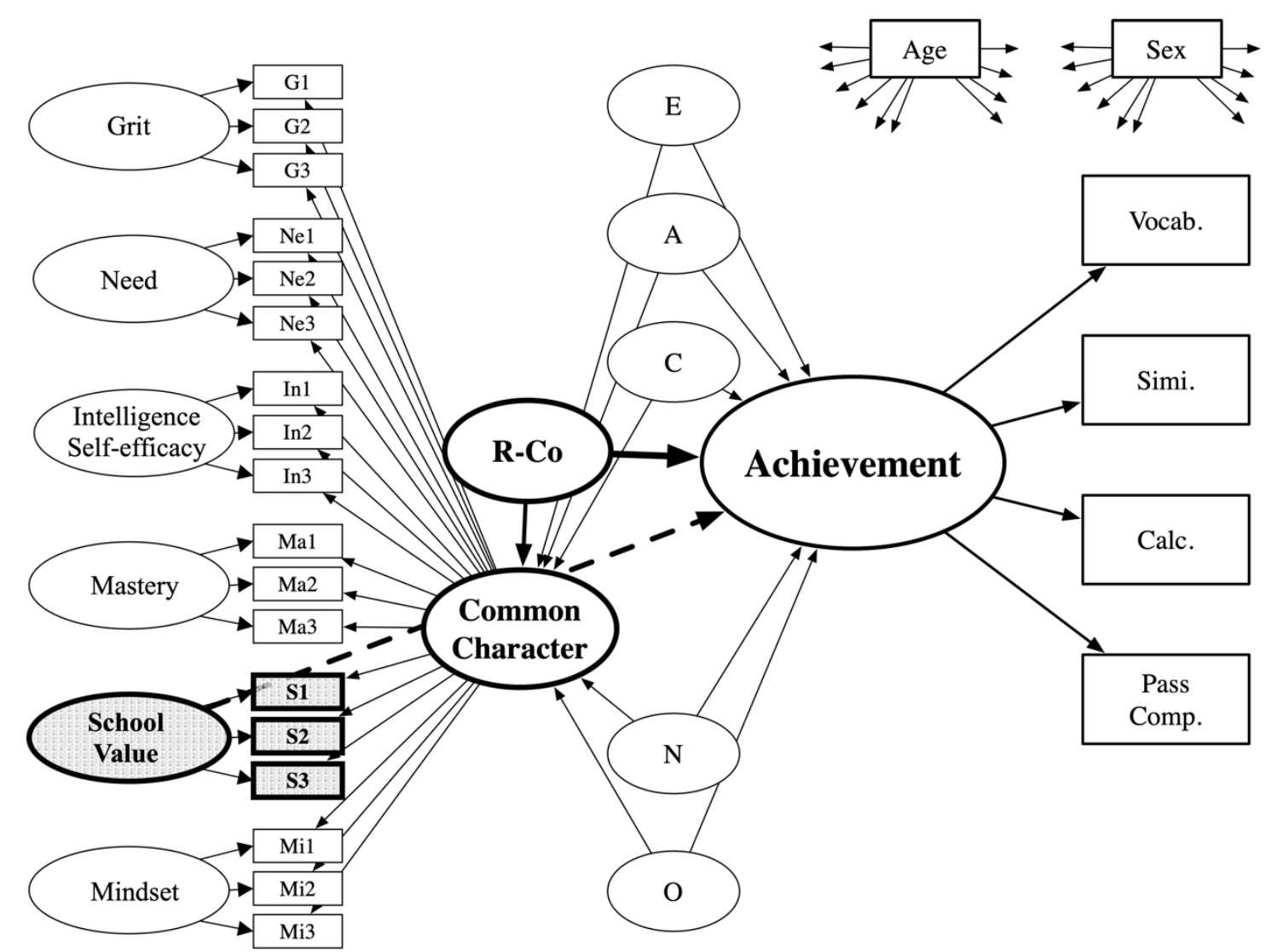

Figure 2. Example structural equation model testing incremental prediction of the common character factor over and above the Big Five. Note that an additional unique association between school value and achievement is specified. 